\title{
Conceptual Aspects of the Development of Logistics Management as Part of the Customs Authority
}

\author{
Iuliia Valerievna Malevich $^{1} \&$ Natalia Nikolaevna Berezkina ${ }^{2}$ \\ ${ }^{1}$ St. Petersburg State University of Economics (UNECON), St. Petersburg, Russian Federation \\ ${ }^{2}$ Limited Liability Company "Gazprom Transgaz Saint-Petersburg” (Gazprom Transgaz Saint-Petersburg LLC), \\ Saint Petersburg, Russia \\ Correspondence: Iuliia Malevich, St. Petersburg State University of Economics (UNECON), 21, Sadovaya Str., \\ St. Petersburg, 191023, Russian Federation.
}

Received: March 11, 2015 Accepted: March 30, 2015 Online Published: May 22, 2015

doi:10.5539/res.v7n9p32 URL: http://dx.doi.org/10.5539/res.v7n9p32

\begin{abstract}
One of the major problems is high customs and logistics transaction expenses. They account for up to 40 to 70 per cent of the final price of goods according to various calculations. That is despite active application of innovative technologies in customs activities and efforts by the Government of the Russian Federation related to the improvement of customs administration: development of the Road Map, key indicators of the development of international economic activities. All of the above confirms the need for further research, development, and adaptation of logistics toolset when carrying out customs clearance and control operations.
\end{abstract}

Keywords: customs and logistics operations, simulation modelling, logistics approach, purpose of the delivery, checkpoints

\section{Introduction}

Economic reforms that started in Russia during the 1990s could not but reflect the customs operations. Customs clearance procedure changed towards the free market model. It is worth mentioning that during the past years the government of the Russian Federation, scholars, and professionals reached significant results in applying the logistics approach towards optimization of customs procedures.

Logistics approach towards organization of customs clearance of freight and customs clearance procedures includes material, information and financial flows, determination of the technology of optimal transfer of goods across the customs border, development of standard requirements towards both customs procedures as well as the participants of the delivery chain.

Logistization of customs procedures covers the wide scope of issues:

- Managing material export and import flows;

- Financial aspects of logistics in pricing regulations;

- Information support and maintenance of customs operations;

- Customs and related operations - logistics services, etc.

Another direction that achieved some results is information support of customs regulations. In Russian Federation, scholars and practitioners in the area of software support have achieved significant amount of applications that allow ensuring information support of customs clearance, control, payments, decision-making, etc.

Major information systems of customs authorities that ensure automation of key processes of customs service operations include the following:

1) Customs declaration of goods, including declaration of products via the Internet. Implementation of digital declaration was the major condition to enter the Customs Union and the World Trade Organization.

2) Preliminary informing of customs authorities on goods proposed to import and customs control of transit freight of goods in the territory of the Russian Federation. 
Another aspect for which significant results have been gained was the developments related to increase safety of international supply chains, in particular those developed by the World Trade Organization. Apparent advantage of framework standards is the fact they allow increasing the level of supply chain safety, cutting down the time needed to move the freight along the chain, widening the capabilities of customs authorities to discover high-risk deliveries for their further processing, and increasing the efficiency of products administration. In addition, they speed up the process of customs processing and clearance of freights. In the end, this allows for significant savings on logistics expenses.

Another step to optimize customs operations was the Federal Law No. 394 as of June 29, 2011, according to which customs authorities were granted the rights for actual transport and documentary quarantine and sanitary, quarantine and phytosanitary and veterinary control at the checkpoints.

At the same time, despite the active application of innovative technologies in customs regulations, time and financial expenses of the participants of international trade are currently not comparable with the same expenses of the developed countries, thus demonstrating the need for further research in this direction.

\section{Literature Review}

Different countries use different approaches towards the management of supply chains and decreasing actual costs. It is well known that the core logistics strategies are as follows (Sergeyev \& Sergeyev, 2003):

- Minimization of overall costs within the supply chains;

- Increase of quality of logistics services;

- Increased flexibility and reaction time;

- Maximization of profits.

Logistics Management Board declared the following list of logistics functions, including service (non-material) flows, which stimulate the development of logistics approaches in service area, since most links of logistics chain are service in nature (Samolaev, 2008). They include various logistics intermediaries: transport and freight forwarders, terminals, customs structures within the management chain of export and import process flows.

Customs operations are not only related to significant financial expenses, but also require significant time to process. At that, many specialists presume that only up to $10 \%$ of time within the supply chains is spent on value-adding operations, whereas the remaining $90 \%$ are spent on transactions that increase expenses, such as customs clearance operations, in particular. Therefore, one of the most important tasks is to decrease the duration of customs clearance and control of foreign trade freights.

One of the ways to resolve the abovementioned issues related to the supply chain of foreign trade is to use the "just-in-time" logistics concept when organizing customs freight processing and customs clearance operations.

Many researchers (in particular M. Christopher, 2005) pointed out that the "just-in-time" concept is aimed on synchronization of the work of all chain elements, to early identify demands for freight shipment orders, to ensure strict discipline of contractual relations.

Despite the significant number of works dedicated to this logistics theory aspect, there are a number of issues left behind. In particular:

- It is well known, that "just-in-time" presumes integration of all functions and operations of the supply chain, but the available sources do not provide actual examples of implementation of the integrational component;

- Issues of optimization of customs and logistics operations at various supply chain stages are under researched, including when processing goods and vehicles at the customs checkpoints.

\section{Methods}

\subsection{Implementation of the "Just-in-Time" Logistics Concept during Customs Clearance of International Freights}

In our opinion, one option to optimize customs operations in supply chains is involvement of customs surrounding business structures to create specialized customs and logistics terminals (CLTs), which may become the landmark of the entire Russia.

Moreover, these will correspond completely with the implementation of the Customs clearance concept and customs control of goods at the places adjacent to the national border of the Russian Federation. The purpose of the concept is to improve the customs administration by implementation of new technologies of customs processing into the practice of customs clearance, as well as infrastructural development of borderline regions of the Russian Federation, decrease of transport loads of the major cities of the Russian Federation. 
Building CLTs shall help to use various schemes of flow interactions:

- Delivery to the region by long distance transport, processing of specific types of freight at the customs terminal of the junction point (border crossing point) in accordance with the legislative requirements;

- Deliver by the mainstream transport to the territory of the region, overhaul without processing and customs clearance in the transportation point;

- Delivery by the mainstream transport to the region's territory, processing and/or customs clearance of part of the cargo at the transportation point, particularly at the CLT.

The research shows that the delivery to the CLT does not only increase the length of the logistics cycle, but also leads to lower time and therefore financial expenses, because the technically equipped CLT in accordance with the modern requirements can perform operations much faster. Besides, as part of the CLT it is possible to deploy logistics, concepts, methods, models, and technologies. In particular, "just-in-time" concept of time slotting, RFID technologies, etc.

For the purposes of this research, we suggest integration of the following functions and operations for the delivery of international freight: transactions of customs clearance, control, and delivery under the customs control, in other words, transportation and storage functions. Overall, the approach to formation of the "just-in-time" model includes the following steps (Malevich, 2010) (Table 1).

Table 1. Major stages of implementation of the "Just-in-Time" logistics concept when customs processing international freight

\begin{tabular}{lll}
\hline No. Stage & Works \\
\hline $1 \quad$ Gathering and processing statistical data & $\begin{array}{l}\text { Formation (and processing) of database, which reflects actual } \\
\text { state of business processes on timely parameters of all customs } \\
\text { clearance and control operations }\end{array}$
\end{tabular}

2 Calculation of statistical parameters of the cycleDetermination of duration of the given time gap, mean value, by time gaps mean-square deviation for each operation

3 Determination of cycle duration with the given "Just-in-Time" is viewed taking into account confidence limits confidence probability of the cycle time.

4 Determination of time required to carry out theAssessment of upper and lower limits of the gap. "just-in-time" cycle

5 Evaluation of performance probability

Calculation of probability to complete the cycle of operations taking into account the upper and the lower limits of the gap.

The use of the "just-in-time" logistics concept for the customs processing of international freight allows optimizing not only time, but also financial expenses in the global supply chains. It is known that the major principle in evaluation and optimization of logistics expenses is that the information on costs can be used alongside with the information on time characteristics of logistics operations (Malevich \& Plastunyak, 2008).

Complex assessment of these two ratios allows optimizing costs in supply chains by determination of operations that initiate inefficient costs.

\subsection{Methodical Approach to Optimization of the Customs Point Work at the CLT Based on the Time-Slotting Technology}

Since there exists the risk of failure to perform operations on time, which is the major problem of implementation of the "just-in-time" concept for customs processing of international freight, it seems reasonable to use information technologies in customs sphere. In particular, this helps to deploy not only the modern documental traceability of the process (digital declaration technologies, etc.), but also allow efficient planning of the work of the customs points and follow operations in real time mode.

Therefore, efficient implementation of the "just-in-time" concept requires optimization of the incoming and outgoing traffic flow, in other words, to spread the cargo freight evenly at the customs terminals throughout the entire time of customs clearance. 
One of the possible solutions to this problem is to implement the "time-slotting" technology at customs and logistics terminals. As applied to the customs and terminal processing of international freights, time slot can be represented as a period of time, a slot, which is provided to perform a specific operation and scheduled beforehand. Time-slot is limited in time for both the beginning and the end. Duration of the slot is determined by the duration of customs clearance or control operation. It is reasonable to apply this technology to the "customs processing" process, since, currently, there is overload at the customs points, lack of order in processing of freights that arrive to the terminals.

Let us review the methodological approach to optimization of customs point operations based on the time-slotting technology. Core principle of the technology is maximum satisfaction of demand and client needs in timely processing of the requests, taking into account the limitations on production capabilities of the customs point.

Calculation of time slots is done based on the solution of task for optimal planning of time slots loading. In this case, the calculation model can be provided in form of the stages (Table 2).

Table 2. Major stages of implementation of time-slots calculation model and optimization of the plan for the customs terminal service

\begin{tabular}{|c|c|c|c|}
\hline No. & Stage & Explanation & Calculation formula \\
\hline$\overline{1}$ & $\begin{array}{l}\text { Collection and } \\
\text { processing of the } \\
\text { incoming data. }\end{array}$ & $\begin{array}{l}\text { Source data: } \\
\text { - Maximum capacity of the } \\
\text { customs point; } \\
\text { - Demand for service; } \\
\text { - Customs clearance service } \\
\text { plan. }\end{array}$ & - \\
\hline 2 & $\begin{array}{l}\text { Setting the goal and } \\
\text { database preparation in } \\
\text { Excel }\end{array}$ & $\begin{array}{l}\text { - Search for optimal plan of } \\
\text { time-slot loading based on the } \\
\text { principle of maximum demand } \\
\text { meeting; } \\
\text { - Search for the optimal service } \\
\text { plan ("flattening service plan"). }\end{array}$ & $\begin{array}{l}\sum_{i=1}^{n} Z_{i} \geq \sum_{i=1}^{n} X_{i} \\
\text { where } X_{i} \text { means demand for processing of requests } \\
\text { in the i time-slot; } \\
Z_{i} \text {-limitation on the load of i time-slot under } \\
\text { technical, technological and organizational reasons; } \\
\text { n-number of time slots. }\end{array}$ \\
\hline 3 & $\begin{array}{l}\text { Optimization of time } \\
\text { slots loading }\end{array}$ & $\begin{array}{l}\text { Optimization and accounting for } \\
\text { limitations }\end{array}$ & $\begin{array}{l}S=\sum_{i=1}^{n}\left(Y_{i}-X_{i}\right)^{2} \mathbb{B} \min \\
\text { Limitations: } \\
Y i \leq Z i, Y i \geq 0, i=1 \ldots n \\
\sum_{i=1}^{n} Y i \geq \sum_{i=1}^{n} X i\end{array}$ \\
\hline
\end{tabular}




\begin{tabular}{|c|c|c|c|}
\hline No. & Stage & Explanation & Calculation formula \\
\hline$\overline{4}$ & $\begin{array}{l}\text { Optimization of the } \\
\text { service plan }\end{array}$ & $\begin{array}{l}\text { Optimization of the service plan } \\
\text { based on balancing turnover, } \\
\text { taking into account existing } \\
\text { limitations. }\end{array}$ & $(Y i-C o X i)^{2} ß \min$ \\
\hline
\end{tabular}

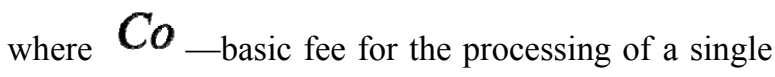
request (\$ per unit);

\section{$\mathrm{Ci} \ldots$ new fee for the processing of a request in the i's} time slot.

Limitations:

\section{$C i \geq d, i=1 \ldots n$; \\ $\sum_{i=1}^{n} C_{i} Y_{i}=\sum_{i=1}^{n} C o X i$}

where $d_{\text {means the minimum available fee }(\$ \text { per }}$ unit).

5 Correction (if necessary)
Recurring procedure of plan corrections, which practically means introduction of the feedback into the model

\section{$X_{i}^{\prime}>Z_{\lim }$}

where $X_{i}^{\prime}$ means new demand on request processing;

$Z \lim$ means the limit of requests in the time-slot, determined by the production capability;

$$
S^{\prime}=\sum_{i=1}^{n}\left(Y^{\prime} i-X^{\prime} i\right)^{2} \mathbb{R} \min
$$

Limitations:

$$
\begin{aligned}
& C^{\prime} i \geq d, i=1 \ldots n \\
& \sum_{i=1}^{n} C^{\prime} i Y^{\prime} i=\sum_{i=1}^{n} C i X^{\prime} i
\end{aligned}
$$

Application of the "time-slotting" technology in customs terminals will first allow levelling up the load, second, making customs actions during the cargo clearance more transparent; third, formalizing relations between customs representative and customs itself; fourth, and most important, decreasing the time spent on customs clearance and simplify the entire scheme. 


\subsection{Modelling Customs and Logistics Operations at the Checkpoints on the Customs Border Using the Anylogic Environment}

Recent years show progressive growth of cargo and passenger traffic going through the checkpoints at the territory of the Customs Union. The load is most significant at the outside border with European Union countries. Thus, currently Russian Federation checkpoints operate intensively, and, actually, they have overreached their capacity, because the infrastructure and technologies for the passage of people, vehicles, and cargo were created decades ago and were not designed for the current cargo and passenger loads. Besides, implementation of tasks and functions required from the state controlling authorities in accordance with the current legislation is complicated, because the typical technologic schemes do not correspond with the current situation.

In the given situation, in order to assist the international trade, optimization of time parameters of customs operations in the supply chains of international freight, issues of modernization, design and construction of new checkpoints, use of modern information technologies by state control authorities, application of the most advanced technical control means, etc. become very current. At the same time, despite the importance of technological influences, reconstruction of existing and construction of new checkpoints is a long and costly process, whereas the problem of passing goods and vehicles through the customs border is already significant. Besides, process of decision making on modernization and reconstruction of checkpoints bears risks, that some factors will not be accounted for, and their influence will only become obvious with the passage of time.

In our opinion, there are ways to solve some of the above-mentioned problems; in particular, application of methods of logistics theory alongside with modern modelling tools shall significantly reduce the time needed to pass the border.

In order to minimize the risks of mistakes when developing plans for modernization, reconstruction, technical re-equipment, and in order to optimize the technology of operations of the checkpoints and consequently to decrease time and financial losses for both participants of international trade as well as for the state, we suggest using simulation modelling (SM).

Main advantage of the simulation modelling is that the experiments are made on the created model rather than on the existing system. Processes are depicted as if they were actually taking place, which allows simulating the system behaviour without time and financial losses. Simulation modelling allows to model various situations of making various actions, thus slowing down or increasing their pace, depending on the behaviour of a system under study, and to analyse the results.

Complex of technological influences related to goods and vehicles processing when entering the customs territory can be shown in for of enlarged typical scheme of carrying out operations (customs, borderline, transport, etc.) by the state controlling authorities.

Technological scheme is characterized by the existence of casual relations, time parameters of structural behaviours. All parts of the process can be described using the discrete and event, or process-oriented modelling implemented in the Any-Logic environment.

Time to process consequential operations depends on the fact that participants of international trade follow the prohibitions and limitations as set forth by the customs legislation. Therefore, it is determined that the technological scheme is characterized by the existence of casual relations, time parameters of its elements' behaviour, which study is quite complicated. However, this becomes possible due to the modern developments in the support of logistics solutions. One of such developments is the Any-Logic software, which allows creating models of various complexity and to present them vividly in form of interactive animations.

Thus, we have developed a discrete-event model of performance of customs and logistics operations based on the example of one of the checkpoints, which parameters were set up in accordance with the expert data gathered by surveying various participants of international trade.

Model (Figure 1) is a structural diagram, which consists of several elements-active objects used to develop flow charts that simulate customs and logistics operations. Individual parameters were determined for the model objects, which correspond with specific operations. For example, for vehicles arriving to the international automobile border-crossing point for customs and logistics operations, we have set various intensity of arrival, amount, conditions of carrying out customs and logistics operations, etc.

Due to the need to analyse the results of time measurements as spent on customs and logistics operations, we have introduced additional parameters to the objects needed to accumulate statistics, which allows determining ways for further optimization. 
Collection of data takes place using the net time of performance of customs and logistics operations at the international automobile border-crossing checkpoint, as well as using the overall time (including queuing time before entering the territory of the checkpoint).

\section{Results}

The outcome of the experimental work on then simulation model, the data were acquired online and overall time for vehicles that pass the border under various schemes:

- Under the simplified scheme (only documentary control takes place at the checkpoint);

- Sent to the $10 \%$ customs inspection of customs and logistics operations;

- Sent to customs inspection using the tools for customs control, including inspection and control complexes.

The experiment took place over 576 hours.

Average net time and average overall time (variation range) of the performance of customs and logistics operations under the simplified scheme were between 50 and 52 minutes, and between 52 minutes and 3.2 hours respectively.

For vehicles sent to the $10 \%$ inspection in the process of operational performance, it was between 5.2 and 22.3 hours and between 5.3 and 22.5 hours. Moreover, for vehicles sent for inspection using the inspection and control complexes-from 2.2 to 8.3 hours and from 2.2 to 10.36 hours.

Until the moment the queue formed at the entrance of the checkpoint, values of both ("net" and "overall" time) will be the same.

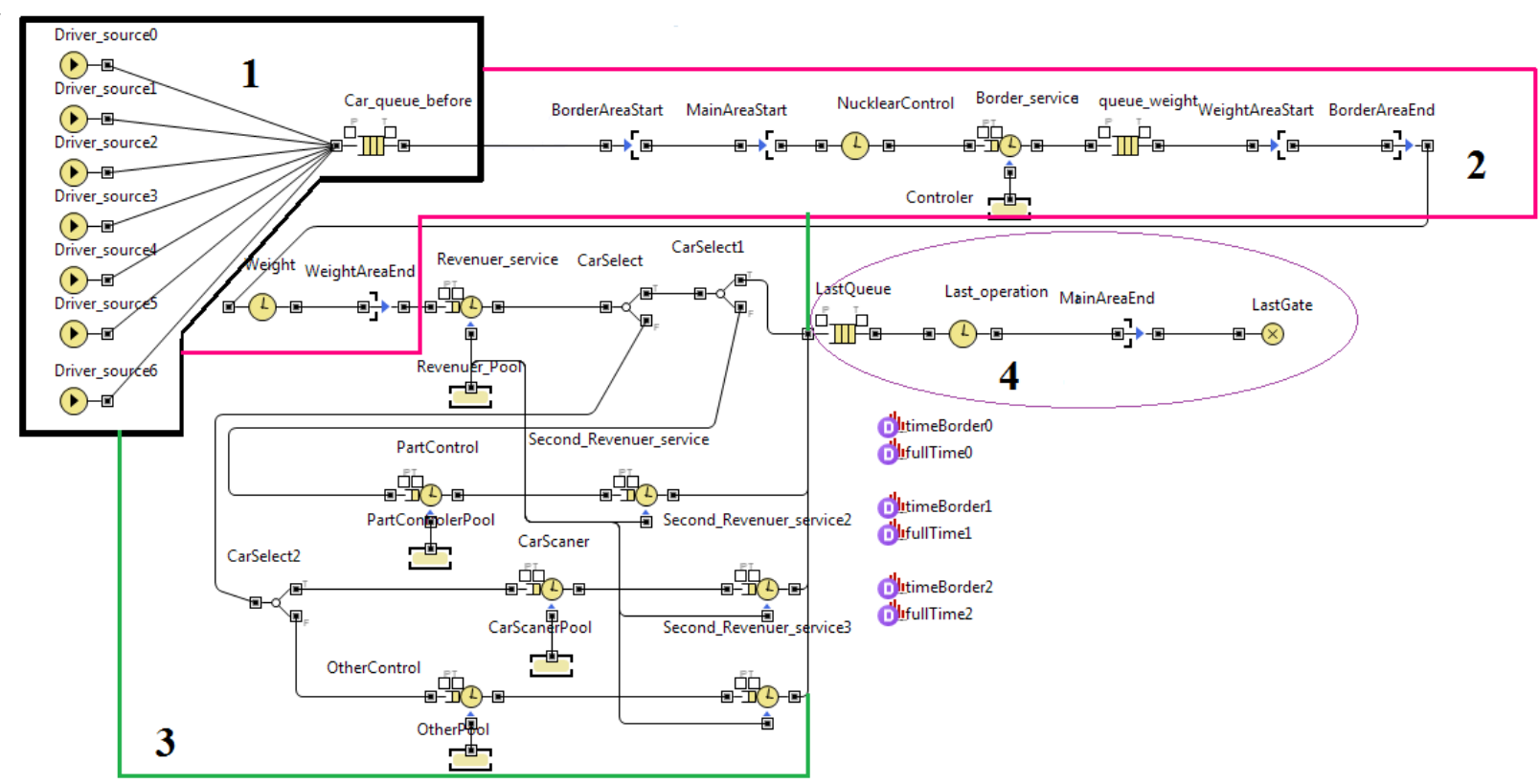

Figure 1. Simulation modelling of performance of customs and logistics operations at the international automobile border-crossing checkpoint at the entrance to the Russian Federation, as implemented in the Any-Logic environment

\section{Discussion}

The obtained results reflect on the existing situation in servicing the cargo traffic at the checkpoint. It is obvious, that the time of processing of a vehicle with the cargo that only requires documental customs control is significantly below the same time in case if other forms of customs control are used, which is obvious.

However, the main result is that the designed model allows holding various experiments on changing the number of employees of state controlling authorities at various stages, to increase the technical equipment of the international automobile border-crossing checkpoint (number of tools for customs control, locations for 
inspections, weighting devices, etc.).

Experimenting with variable data, it is quite easy to implement technically-it is necessary to measure the parameters of the objects responsible for particular operations.

In case if the sequence of operations is proposed to change and for evaluation of practicability of such technological changes, it is necessary to rebuild the structural chart and to measure the time. At that, the new (designed) model shall feature similar parameters of inflow and technical equipment of the checkpoint to the source model, so that to show the nature of dynamics of change of time for operational performance.

In both cases, Any-Logic allows to receive preliminary data for further decision making on possible ways to increase the capacity of the checkpoints without financial expenses on one side, and ensuring compliance with the requirements of national and economic state security on the other side. Level of risk to make a mistake when making final decisions depends on the depth of model design, including the trustworthiness of time parameters input in the model, which optimize its functioning.

\section{Conclusion}

During the past decade the concept of integrated logistics had been fast developing, which is applied for end-to-end core and support flows control in the integrated business structure. At the same time, these issues are seen as part of internal company integration and cooperation, whereas it is worth speaking of integration of logical functions and operations in supply chains as a whole, which means optimising not the specific elements, but the chain itself. Implementation of the integrational component in our opinion is possible for customs and logistics systems of countries and regions that have both the potential, which promotes equal competition on one side, and create conditions for horizontal spread of organizational and technical innovations on the other side.

One of the potentially promising areas of further development in our opinion is coordination of work of all members of the supply chains based on the unified technological process.

Optimal solution of issues discussed above can be reached using the models and methods of logistics theory.

It is necessary to form an adequate analytical toolset - collection of models and methods that allow for objective evaluation of capabilities and potential of development, based on calculations rather than on hypotheses.

Implementation of logistics approach in the supply chains of international trade freights shall allow decreasing the logistics expenses.

\section{References}

Bochkarev, A. A. (2008). Supply chain planning and modelling: Workbook (p. 192). Moscow: Alpha-Press.

Brodetsky, G. L. (2006). Logistic systems modelling. In Optimal solutions under risk (p. 376). Moscow: Vershina.

Christopher, M. (2005). Logistics and management of the supply chains (p. 316). Saint Petersburg: Piter.

Glukhov, V. V., Mednikov, M. D., \& Korobko, S. B. (2005). Special literature. In Mathematics methods and models for management: College textbooks (p. 528). Saint Petersburg: Lan'.

Gorev, A. E. (2004). Information systems and technologies in logistics: Object oriented approach to modelling and managing supply chains. Supply chain logistics and management, 4-5(5), 5-27.

Imitational modelling and solution of optimization tasks [digital source]. (2012). Retrieved from http://www.mivlgu.ru/conf/zvor_2012/section.html

Kiseleva, M. V. (2009). Simulation modelling of systems in the Any-Logic environment: Guidance manual (p. 88). Yekaterinburg: UGTU-UPI.

Lukinsky, V. S., Lukinsky, V. V., Malevich, Y. V., Plastunyak, I. A., \& Pletneva, N. G. (2007). Models and methods of the logistics theory (p. 448). Saint Petersburg: Piter.

Lukinsky, V. V., Malevich, Y. V., \& Plastunyak, I. A. (2012). Models and methods for managing transportation, terminal, and customs operations in the supply chain: Monograph (p. 140). Saint Petersburg: SPbGIEU.

Malevich, Y. V. (2008). Application of logistics concept "just-in-time" to processing customs procedures in the products' supply chains. Modern economic and social development: Problems and perspectives-Scientists and specialists of Saint Petersburg and Leningrad Region for the St. Petersburg Economic Forum.

Malevich, Y. V. (2010). Methodology for managing logistics functions in supply chains. In Dissertation introduced in candidacy for the academic title of the doctor of economic science. Saint Petersburg: SPbGIEU.

Malevich, Y. V., \& Plastunyak, I. A. (2008). On the issue of decreasing logistics expenses in supply chains of 
imported freights. In V. S. Lukinsky, S. A. Uvarov, \& E. A. Koroleva (Eds.), Logistics: Tendencies of modern development: 7th international scientific and practical conference (Report thesis). Saint-Petersburg: SPbGIEU.

Multiple approaches to simulation modelling [Digital source]. (n.d.). Retrieved from www.anylogic.ru

Order of the Ministry of Transportation of the Russian Federation No. 177 dated 09.10.2009. (2009). On approval of the typical scheme of organization of passage of vehicles, freights, goods and animals through the state border of the Russian Federation in automobile checkpoints [Digital source]. Retrieved from http://6pl.ru/fito/pMt_177.htm

Parfenov, A. V., \& Smirnova, E. A. (2007). Customs business. In Practicum: Workbook (p. 78). Saint Petersburg: $S P b G U E F$.

Samolaev, Y. N. (2008). Basics of customs logistics: Workbook (p. 304). Moscow: Alpha-M.: INFRA-M.

Sergeyev, V. I., \& Sergeyev, I. V. (2003). Logistics systems of supply chain monitoring:Workbook (Higher Education series) (p. 172). Moscow: INFRA-M.

The Customs Code of the Customs Union (appendix to the Agreement on the Customs Code of the Customs Union executed at the highest level by the Decision of Interstate Council of Eur As EC No. 17 dated 27.11.2009) (as amended on 16.04.2010) [digital source]. (2010). Retrieved from http://www.consultant.ru/document/cons_doc_LAW_100808/

The Federal Law No. 311-FZ dated 27.11.2010. (2010). On customs regulations in the Russian Federation [digital source]. Retrieved from http://www.consultant.ru/document/cons_doc_LAW_163984

Zaitsev, E. I. (2010). Role of information systems and technologies in logistics. In Materials of the international research and practice conference dedicated to the $10^{\text {th }}$ anniversary of the International logistics centre of the State University-Higher School of Economics [Logistics and managing supply chains-Anti-crisis economic tools] (pp. 128-131). Moscow: SCM Consulting Publishing House.

\section{Copyrights}

Copyright for this article is retained by the author(s), with first publication rights granted to the journal.

This is an open-access article distributed under the terms and conditions of the Creative Commons Attribution license (http://creativecommons.org/licenses/by/3.0/). 